\title{
Theory of consumption value in identifying the role of color in product labeling
}

\author{
W. Swasty \& M. Mustafa \\ Universiti Sains Malaysia, Pulau Penang, Malaysia
}

\begin{abstract}
Consumption Value Theory constructs that color is one of the packaging elements that affects the assessment of food products. This theory argues over the causal effect of functional vs. emotional value in product labeling. The main limitation of using colors in product labeling is that it helps with brand identification but fails to provide functional value when its consumers are seen to be driven by emotional value in choosing the product. Previous studies on Consumption Value Theory focus mostly on luxury products but not much is discussed on small medium enterprise (SME) products. Therefore, this study will provide information on the functional and emotional value of color in food product labeling in the SME industry. This study uses a mix-mode approach to investigate the Consumption Value Theory to explain the role of color and design and employ the theory of consumption value to help explain the role of color in the product labeling of food packaging.
\end{abstract}

Keywords: Consumption Value Theory, product labeling, color, SME product, packaging

\section{INTRODUCTION}

Product labeling and packaging are the most visible aspects at the point of purchase. While color is the most visual cue of product packaging since it is the first factor to be noticed by the consumer. Color selection in packaging plays an important role and has a significant impact in attracting consumers attention as it stimulates different aspects of emotional arousal (Beneke et al. 2015). Designers can utilize the use of color as a visual sign for product decisions by understanding how consumers interpret single-cue representations (Kauppinen-Räisänen \& Jauffret 2018).

Many other elements of packaging, such as color, shape, material, and aesthetic appeal may also potentially influence product consumption value (Silayoi \& Speece 2007). However, the main limitation of using colors in product labeling is that even though it helps with brand identification it fails to provide functional value when consumers are driven by emotional value in product selection. This research examines the emerging role of color as value creation in the context of product labeling. There are two primary aims of this study: (1) to examine the importance of colors and their role within branding and value creation; and (2) to map the effect of colors with functional and emotional value and their causal effects on branding. Hence, this paper attempts to address the research question by investigating the theory of consumption value to help explain the role of color in product labeling in packaging.

\subsection{Working definition}

This study will look at and employ certain terms based upon the Consumption Value Theories and other significant design theories to help uncover and explain the issue within the scope of the research. A number of working definitions were identified specifically for the research. The phrase "consumption value" will be used in this study to describe the consumer or customer value as a basis in a marketing perspective. The theory of consumption value is a famous theoretical 
framework to understand the various dimensions that can make preference judgments of a product type or brand choice (Lin et al. 2020), influence purchase decision (Dhir et al. 2020), and motivate the consumers' post-purchase behavior, i.e., loyalty (Poushneh \& Vasquez-Parraga 2019). While a variety of definitions of the term consumption value have been suggested, this paper will use the definition first proposed by Sheth et al. (1991) who saw that brand, product type, and buying decision within a single product category can be determined by different consumption values.

Presently, existing studies on consumption value theory have identified several contexts that affect consumers' intention to buy. These are functional, emotional, social, conditional, and epistemic (Sheth et al. 1991). Functional value is defined as the perception of the consumer of product performance based on durability, reliability, dependability, price, and other physical quality which is expected to be the main driver of the consumer's decision (Sheth et al. 1991; Qasim et al. 2019). Social value is a different approach that acquires social meaning by associating demographic, socioeconomic, and ethnic groups with positive or negative stereotypes. Emotional value is the perceived utility from the potential of an alternative to elicit feelings or affective conditions. Aesthetic options are often associated with emotional meaning. Epistemic value is the perceived utility derived from the possibility of an alternative to arouse curiosity, generate news, or fulfill the desire for knowledge. Conditional value is the perceived utility of an option due to the specific situation, or circumstances of the decision-maker often depends on the condition (Sheth et al. 1991).

\section{METHOD}

This study uses a mix-mode approach to investigate the consumption value theory to help explain the role of color in product labeling in food packaging. The first step in this analysis is to identify and compile secondary sources from papers through the online journal database related to research topics, specifically on color psychology in branding/packaging and labeling in food products/SME products. This study is later cross-referenced to the Consumption Value Theory, which employs specific values: consumption value, functional value, and emotional value. The criteria of the sources are peer-reviewed scholarly papers (journal and proceeding articles) from 1990-2020. The time frame is chosen to reflect Seth et al.'s conceptual framework of consumption value theory published in 1991 and this would allow for comprehensive mapping of changes in design trend and style in packaging design specifically on the usage of colors in labeling. Input from the secondary sources will also inform the next stage of the research which will help frame the case study (which will include product comparison and eye-tracking experiment), survey, and interviews.

\section{RESULT \& DISCUSSION}

\subsection{Previous works}

The color-product meanings interpretation reveals that color has the potential to convey sensory (taste), functional (relief or calmness), hedonic (medicinal cures), and even situational (strong medicine that cures immediately) meanings (Kauppinen-Räisänen \& Jauffret 2018). Another study by Chaouali et al. (2020) suggests that functional value, emotional value, social value, and epistemic value mediate the influence of design esthetics. The current research by Lee et al. (2019) suggests that hedonic value plays an important part in promoting a positive attitude and intention to buy rather than utilitarian value. Moharana and Pradhan (2020) suggest three shopping values, i.e., utilitarian, hedonic, and social value, to build more considerable consumer loyalty, and both marketers and designers need to formulate distinction approaches. Chen and Peng (2018) examine how the consumption value impacts consumers' attitudes and suggest that consumption value can influence the attitudes of the customer, which in turn may affect their behavioral intentions. The prior literature has used the theory of consumption value for examining consumers' decisions as compiled and summarized in Table 1 below. 
Table 1. Prior research related to consumption value.

\begin{tabular}{|c|c|c|}
\hline Author(s) \& Year of Publication & Research Context & Values \\
\hline Sheth et al. (1991) & Cigarettes & functional, conditional, social, emotional, epistemic \\
\hline Holbrook (2005) & photograph & economic, social, hedonic, and altruistic value \\
\hline Smith and Colgate (2007) & Framework for marketing strategy & symbolic/expressive, experiential/hedonic, functional/instrumental, and cost/sacrifice value \\
\hline Tynan et al. (2010) & Luxury brand & symbolic/expressive, experiential/hedonic, utilitarian, cost/sacrifice, and rational value. \\
\hline Choo et al. (2012) & Luxury fashion product & symbolic value, hedonic value, utilitarian value, and economic value \\
\hline Ramayah et al. (2018) & Online shopping & functional, social value, emotional value, epistemic value, conditional value \\
\hline Kirillova and Chan (2018) & Hotels' visual appeal & aesthetic value (classic and expressive) functional value (amenities) \\
\hline Chen and Peng (2018) & Luxury restaurant & functional, financial, hedonic, and symbolic/expressive \\
\hline Eren-Erdogmus et al. (2018) & Luxury fashion brand extensions & functional, hedonic/experiential, and symbolic \\
\hline Wiedmann et al. (2018) & Luxury hotel industry & financial, functional, social, and individual \\
\hline Qasim et al. (2019) & organic food behavior & functional (price and quality), social, conditional, epistemic, and emotional \\
\hline Cha and Seo (2019) & eating-out consumption & hedonic value, utilitarian value \\
\hline Ali et al. (2019) & Green IT product & functional, social, epistemic, emotional, conditional, and religious value \\
\hline Jan et al. (2019) & Green product & ecological, economic, health and safety value \\
\hline Poushneh and Vasquez-Parraga (2019) & smartphone as a smart product & emotional, functional, social, conditional, and epistemic, + monetary value \\
\hline Carlson et al. (2019) & social media retail brand communities & functional, emotional, relational, and entitativity value \\
\hline Amalia et al. (2019) & luxury brand & functional, symbolic, and experiential values \\
\hline Zhang and Zhao (2019) & luxury fashion product & personal value and luxury value: symbolic, experiential value and functional value \\
\hline Lee et al. (2019) & study on cosmetic packaging & social, emotional, quality value \\
\hline Krey et al. (2019) & Smartwatch advertising strategy & functional and ergonomic value, hedonic and symbolic \\
\hline Huang et al. (2019) & Mobile marketing (WeChat) & emotional, functional value, monetary value, guarantee value, social value, design value \\
\hline Rantala et al. (2019) & Digital business & service process-, product-, and cost-related value \\
\hline de Klerk et al. (2019) & Luxury genuine leather products & financial, functional, individual, and social \\
\hline Diallo et al. (2020) & Luxury brand & the functional, social, symbolic value \\
\hline Lin et al. (2020) & Organic Food & functional and emotional \\
\hline Moharana and Pradhan (2020) & hypermarket context (retail) & two dimensions (hedonic and utilitarian) and three dimensions (hedonic, utilitarian, and social) \\
\hline Lim and Kim (2020) & Online shopping & utilitarian and hedonic value \\
\hline Jung et al. (2020) & Sustainable Apparel Products & aesthetic consumption, conspicuous consumption, and utilitarian consumption \\
\hline Omigie et al. (2020) & Mobile Financial Services & utilitarian, hedonic, and personal \\
\hline Chaouali et al. 2020 & Mobile banking & functional, emotional, social, epistemic \\
\hline Dhir et al (2020) & Mobile instant messaging apps & functional and social \\
\hline
\end{tabular}




\subsection{Finding}

In this study, two consumption values will be addressed, i.e., functional and emotional values. The multidimensional approach to the consumption value takes two basic dimensions into account: functional (utilitarian or cognitive value) and emotional (hedonic or affective value) (Lee et al. 2019). They were emphasized by Lin et al. (2020), and the results indicated that both functional and emotional value has an important impact on buying intention. Table 1 does not document all research related to consumption value/customer value yet. However, from Table 1, it can be concluded that functional or utilitarian value and emotional or hedonic value have been used mostly in prior studies which are 29 and 24 number of studies, respectively.

Functional value refers to the product or service design or functions; which is cognitive because it is connected with utility and usability whereas the emotional value is more effective because it is linked to pleasure, entertainment, and interest-based on personal identification of consumers to the brands (Tian et al. 2018; Lim \& Kim 2020). For food product packaging, the functional value can indicate values of the product either perishable or non-perishable products, besides a reflection on the price and quality of the product. Throughout this paper, the term "functional value" refers to utilitarian or cognitive value, while "emotional value" refers to the hedonic or affective value.

This study helps to identify the difference between perceived functional and emotional values and how it influences customers decisions. When launching a new product, designers should pay attention to customers' functional needs and emotional desires (Poushneh and Vasquez-Parraga 2019). A study by Ramayah et al. (2018) indicates that, along with functional value, emotional value plays an instrumental role in online purchase intention. Functional value (especially price and service quality) has the best positive relation to customers' intention to use the internet as a retail platform. Emotional value influences consumers' willingness to buy products online. The subdimensions of consumption values used in past studies in research contexts are slightly different (Jung et al. 2020).

Several previous studies address Consumption Value Theory are mostly on luxury products. Therefore, this study wants to fill in the gap by providing knowledge in functional and personal value of color in food product labeling in the SME context. In addition, the need to strengthen the competitiveness of SMEs in Indonesia is crucial in the global competition era as the ASEAN economic community, as they have a great contribution to national economic growth and lead to improving the Gross Domestic Products (Darwanto et al. 2018).

\section{CONCLUSION}

This study is designed to address a research question and framework on employing the theory of consumption value to explain the role of color in product labeling. Selected studies concerning the theory of consumption value are summarized in Table 1. It may be noted that the consumption value literature from 1990-2020 highlights the functional and emotional value as the key factor in a consumer's decision and the key indicator for a consumer's brand loyalty. As customers perceive functional value, strong emotional links with brands are generated for products (Poushneh and Vasquez-Parraga 2019).

Previous studies address Consumption Value Theory mostly on luxury products. This study clearly highlights the need for further research in the role of color in product labeling in the SME context. The findings described above enhance our understanding and serve as the basis for a research question in color as value creation. This study would benefit from the further emphasis placed on the complexity of contextual usability and answering such research questions as follows.

RQ1. Why is the use of colors important within branding and value creation in SME products in Bandung?

RQ2. What is the effect of colors in the creation of functional and personal value for branding?

The elaborate scope of the research framework outlined above highlights the importance and potential of consumption value in color research. This research-in-progress pioneers analyzing consumers' value published to-date. 


\section{REFERENCES}

Beneke, J. et al. 2015. The role of package color in influencing purchase intent of bottled water Implications for SMEs and entrepreneurs, Journal of Research in Marketing and Entrepreneurship, 17(2):165-192. doi: 10.1108/JRME-05-2015-0030.

Chaouali, W. et al. 2020. Design aesthetics as drivers of value in mobile banking: does customer happiness matter?, International Journal of Bank Marketing, 38(1): 219-241. doi: 10.1108/IJBM-03-2019-0100.

Chen, A. and Peng, N. 2018. Examining consumers' intentions to dine at luxury restaurants while traveling, International Journal of Hospitality Management. Elsevier, 71:59-67. doi: 10.1016/j.ijhm.2017.11.009.

Darwanto, D. et al. 2018. Designing model and strategy for strengthening the competitiveness of small medium enterprises, Etikonomi, 17(1): 69-92. doi: 10.15408/etk.v17i1.6826.

Dhir, A., Kaur, P., and Rajala, R. 2020. Continued use of mobile instant messaging apps: a new perspective on theories of consumption, flow, and planned behavior. Social Science Computer Review, 38(2):147-169. doi: 10.1177/0894439318806853.

Jung, H. J., Choi, Y.J., and Oh, K.W. 2020. Influencing factors of chinese consumers' purchase intention to sustainable apparel products: exploring consumer "attitude-behavioral intention" gap, Sustainability. MDPI AG, 12(5): 1-14. doi: 10.3390/su12051770.

Kauppinen-Räisänen, H. and Jauffret, M. N. 2018 Using color semiotics to explore color meanings, Qualitative Market Research, 21(1): 101-117. doi: 10.1108/QMR-03-2016-0033.

Lee, S. et al. 2019. Communicating authenticity in packaging of Korean cosmetics, Journal of Retailing and Consumer Services. Elsevier Ltd, 48:202-214. doi: 10.1016/j.jretconser.2019.02.011.

Lim, S. H. and Kim, D. J. 2020 Does emotional intelligence of online shoppers affect their shopping behavior? From a cognitive- affective-conative framework perspective, International Journal of Human-Computer Interaction. Taylor \& Francis, pp. 1-10. doi: 10.1080/10447318.2020.1739882.

Lin, J. et al. 2020. Purchasing organic food with social commerce: An integrated food- technology consumption values perspective, International Journal of Information Management. Elsevier, 51. doi: 10.1016/j.ijinfomgt.2019.11.001.

Moharana, T. R. and Pradhan, D. 2020. Shopping value and patronage: when satisfaction and crowding count, Marketing Intelligence \& Planning, 38(2):137-150. doi: 10.1108/MIP-07-2018-0264.

Poushneh, A. and Vasquez-Parraga, A. Z. 2019. Emotional bonds with technology: the impact of customer readiness on upgrade intention, brand loyalty, and affective commitment through mediation impact of customer value, Journal of Theoretical and Applied Electronic Commerce Research, 14(2):90-105. doi: $10.4067 / \mathrm{s} 0718-18762019000200108$.

Qasim, H. et al. 2019. The defining role of environmental self-identity among consumption values and behavioral intention to consume organic food, International Journal of Environmental Research and Public Health, 16:1-22. doi: 10.3390/ijerph16071106.

Ramayah, T., Rahman, S. A., and Ling, N. C. 2018. How do consumption values influence online purchase intention among school leavers in Malaysia?, Revista Brasileira de Gestao de Negocios. Fundacao Escola de Comercio Alvares Penteado, 20(4):638-654. doi: 10.7819/rbgn.v0i0.3139.

Sheth, J. N., Newman, B. I., and Gross, B. L. 1991. Why we buy what we buy: a theory of consumption values, Journal of Business Research, 22(2): 159-170. doi: 10.1016/0148-2963(91)90050-8.

Silayoi, P. and Speece, M. 2007. The importance of packaging attributes: A conjoint analysis approach, European Journal of Marketing, 41(11-12):1495-1517. doi: 10.1108/03090560710821279.

Tian, G. et al. 2018. Old names meet the new market: an ethnographic study of classic brands in the foodservice industry in Shantou, China, Human Organization, 77(1):52-63. doi: 10.17730/1938-3525.77.1.52. 